\title{
Article \\ Dual Aquaporin and Sigma1 receptor (DAS) modulators: new tools for counteracting oxidative stress
}

\author{
Giorgia Pellavio ${ }^{1}$, Giacomo Rossino ${ }^{2}$, Giulia Gastaldi' ${ }^{1}$, Daniela Rossi ${ }^{2}$, Pasquale Linciano ${ }^{2}$, \\ Simona Collina ${ }^{2,+}$, Umberto Laforenza ${ }^{1,+, *}$ \\ 1 Department of Molecular Medicine, Human Physiology Unit, University of Pavia, 27100 Pavia, Italy; \\ giorgia.pellavio@gmail.com, giulia.gastaldi@unipv.it, lumberto@unipv.it \\ 2 Department of Drug Sciences, Medicinal Chemistry and Pharmaceutical Technology Section, University of \\ Pavia, I- 27100 Pavia, Italy; giacomo.rossino01@universitadipavia.it, daniela.rossi@unipv.it, \\ pasquale.linciano@unipv.it, simona.collina@unipv.it \\ * Correspondence: lumberto@unipv.it; Tel.: +39-0382-98-7568 (U.L.) \\ † These authors contributed equally to this work.
}

\begin{abstract}
Specific aquaporins (AQP), called peroxyporins, play a relevant role in controlling $\mathrm{H}_{2} \mathrm{O}_{2}$ permeability and ensure reactive oxygen species wasting during oxidative stress. Another target involved in oxidative stress is the Sigma1 Receptor (S1R), since its activation is triggered by oxidative or endoplasmic reticulum stress. Herein we evaluated the effect of S1R modulators on $\mathrm{AQP}$-dependent water permeability in the presence and in the absence of oxidative stress. Applying stopped-flow light scattering and fluorescent probe methods, water and hydrogen peroxide permeability in Hela cells have been studied. Results evidenced that S1R agonists can restore water permeability in heat-stressed cells and the co-administration with a S1R antagonist totally counteracted the ability to restore the water permeability. All compounds except one were able to counteract the oxidative stress of HeLa cells specifically knocked down for S1R. Taken together, our results support the hypothesis that the investigated compounds act as dual aquaporin and Sigma1 receptor (DAS) modulators. The finding that small molecules can modulate both AQP and S1R opens a new direction toward the identification of innovative drugs able to regulate cell survival during oxidative stress in pathologic conditions, like cancer and degenerative diseases.
\end{abstract}

Keywords: peroxiporins; oxidative stress, hydrogen peroxide, water channels, Sigma1 receptors, Sigma1 receptor modulators, neurodegenerative diseases

\section{Introduction}

Hydrogen peroxide $\left(\mathrm{H}_{2} \mathrm{O}_{2}\right)$ is the most abundant and stable reactive oxygen species (ROS) in living cells [1]. While at low physiological concentrations $\mathrm{H}_{2} \mathrm{O}_{2}$ may act as signaling molecule, its accumulation within cells, due to an unbalance between ROS production and scavenging, causes oxidative stress [2-6]. When oxidative stress occurs, the $\mathrm{H}_{2} \mathrm{O}_{2}$ produced must be eliminated either by intracellular antioxidant systems or by outflow through the plasma membrane. Moreover, $\mathrm{H}_{2} \mathrm{O}_{2}$ is a signaling molecule involved in various physiological processes through autocrine or paracrine mechanisms [1]. $\mathrm{H}_{2} \mathrm{O}_{2}$ crosses the biological membranes through a diffusion-facilitating channel mechanism [1]. Aquaporins (AQPs) are integral membrane proteins forming channels in the biological membranes involved in the transport of water and small molecules. Some of them, have been recognized to allow the transmembrane diffusion of $\mathrm{H}_{2} \mathrm{O}_{2}[1,3,7]$ and for this reason named peroxiporins. To date five AQPs showed $\mathrm{H}_{2} \mathrm{O}_{2}$ permeability: AQP3 [8-11], AQP5 [12], AQP8 [4, 13], AQP9 [14] and AQP11 [15]. 
The control of peroxiporins-mediated $\mathrm{H}_{2} \mathrm{O}_{2}$ permeability seems to have a great importance in regulating cell signaling and survival during oxidative stress [4, 16-18]. For living cells, the functioning of peroxyporins is critical to ensure ROS wasting and is considered an antioxidant system. Various cellular stress conditions, including heat and incubation with $\mathrm{H}_{2} \mathrm{O}_{2}$, reduce the AQPmediated $\mathrm{H}_{2} \mathrm{O}_{2}$ transport [4, 16-18]. Recently, a number of natural antioxidants, such as flavonoids, flavanones and terpenoids, has been identified as AQPs modulators [17]: addition of such compounds, during or after heat-treatment, is able to prevent or reverse the AQP permeability [17]. This suggests the possibility to chemically modulate the pore gating of peroxiporins, supporting the idea that AQPs are druggable targets.

As a whole, these results open new direction to the development of novel therapeutic treatments to regulate cell signaling and survival during oxidative stress in normal and pathologic conditions, like cancer and degenerative diseases $[19,20]$.

As a part of our current research [21-25], we have recently identified Sigma1 Receptor (S1R) modulators able to exert antioxidant activity in cellular models [17, 24, 26-28]. S1R is a molecular chaperone residing at mitochondria-associated endoplasmic reticulum (ER) membrane [29]. Here, S1R modulates calcium transfer from ER to mitochondria through inositol triphosphate receptor (IP3R). As a consequence, this boosts nicotinamide adenine dinucleotide cofactor (NADH) levels through the tricarboxylic acid cycle, essential for ATP production by oxidative phosphorylation. Interestingly, it has been demonstrated that also AQP8 and AQP11 are localized in mitochondria [29, 30] and ER [15], respectively and possess $\mathrm{H}_{2} \mathrm{O}_{2}$ permeability.

Upon activation, S1R can translocate and interact with different client proteins, thus modulating diverse signaling pathways connected to cell survival and excitability. For this reason, S1R has been regarded as a promising therapeutic target and is currently being investigated for a number of complex multifactorial pathologies, such as neurodegeneration and neuropathic pain [30-32]. Accumulating evidence suggests that modulation of S1R is an effective strategy to counteract oxidative stress, although mechanisms responsible for the antioxidant effects exerted by S1R have not been completely clarified yet [33-35]. It protects cells from oxidative stress by reducing levels of reactive oxygen species, and it provides additional layers of protection during ER stress in addition to its chaperoning activities [29,36]. S1R modulators are under investigation for treating several diseases involved in oxidative stress [37] such as cardiovascular diseases, neurodegenerative disorders, diabetes, ischemia/reperfusion, Alzheimer's [38-40] and CNS inflammatory conditions associated with cocaine and HIV [40,41]. Summarizing up, for many of these debilitating conditions, oxidative stress is one of the underpinning mechanisms, and therapies implementing antioxidant effects may enhance healing potential. We have recently discovered a series of aryl aminoalkyl ketones endowed with good S1R binding affinity and antioxidant properties, as viable neuroprotective pharmacological tools [26]. Of note, the potent S1R agonist, called RC-33, identified in our lab is currently under investigation in vivo for its potential against Amyotrophic Lateral Sclerosis and for recovery of the damage of Spinal Cord Injury [21].

Moving from these considerations, and prompted by the evidences that AQP8 and AQP11, are localized in mitochondria [42, 43] and ER [15], respectively, in the present paper we studied the potential of S1R modulators as AQPs interfering compounds. As a first step we studied the in vitro effect of the well-established S1R agonists PRE-084 and RC-33 (both in its racemic and $(R)$-configured form), and of the S1R antagonist NE-100, on AQPs. Afterwards, the investigation was extended to three in-house developed S1R ligands (compounds 1-3, Figure 1), for which additional intrinsic antioxidant properties have already been demonstrated [26]. To the best of our knowledge, this is the first study aimed at evaluating the effect of S1R modulators on AQP-mediate antioxidant mechanism. 


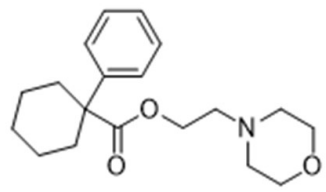

PRE-084

S1R agonist

$\mathrm{Ki}=53.2 \mathrm{nM}$

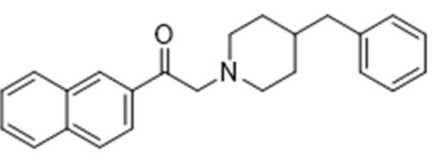

1

$\mathrm{K}_{\mathrm{i}} \mathrm{S} 1 \mathrm{R}=27 \mathrm{nM}$

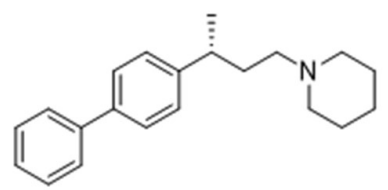

(R)-RC33

S1R agonist

$\mathrm{Ki}=1.8 \mathrm{nM}$

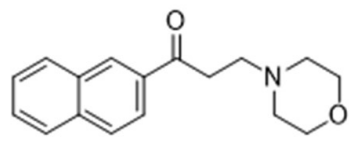

2

$\mathrm{K}_{\mathrm{i}} \mathrm{S} 1 \mathrm{R}=9.0 \mathrm{nM}$

Figure 1. Chemical structures of S1R ligands tested in this study to evaluate their AQPs-mediated antioxidant effect.

\section{Materials and Methods}

\subsection{Chemicals and reagents}

Reagents and solvents for synthesis, TLC and NMR were purchased from Sigma Aldrich. Silica gel for flash chromatography $(60 \AA, 230-400$ Mesh) was purchased from Sigma Aldrich. Solvents were evaporated at reduced pressure with the Heidolph Laborota 4000 Efficient equipment. Analytical thin layer chromatography (TLC) analyses were carried out on silica gel pre-coated glassbacked plates (TLC Silica Gel 60 F254, Merk) impregnated with a fluorescent indicator, and visualised with the instrument MinUVIS, DESAGA ${ }^{\circ}$ Sastedt-GRUPPE by ultraviolet (UV) radiation from UV lamp $(\lambda=254$ and $366 \mathrm{~nm}$ ) or by stain reagents such as Ninidrine and Cerium Molybdate. NMR were measured at room temperature $\left(15^{\circ}-25^{\circ} \mathrm{C}\right)$ on a Bruker Advance $400 \mathrm{MHz}$ spectrometer, using tetramethylsilane (TMS) as internal standard and a BBI $5 \mathrm{~mm}$ probe. All raw FID files were processed with Top Spin program from Bruker and the spectra analysed using the MestRenova 6.0.2 program from Mestrelab Research S.L. Chemical shifts are expressed in parts per million (ppm, $\delta$ scale). $1 \mathrm{H}-$ NMR spectroscopic data are reported as follow: chemical shift in ppm (multiplicity, coupling constants $\mathrm{J}(\mathrm{Hz})$, integration intensity). The multiplicities are abbreviated with $\mathrm{s}$ (singlet), d (doublet), $\mathrm{t}$ (triplet), $\mathrm{q}$ (quartet), $\mathrm{m}$ (multiplet) and brs (broad signal). The chemical shift of all symmetric signals is reported as the centre of the resonance range. 13C-NMR spectroscopic data are reported as follows: chemical shift in ppm. UPLC-UV-ESI/MS analyses were carried out on a Acuity UPLC Waters LCQ FLEET system using an ESI source operating in positive ion mode, controlled by ACQUIDITY PDA and 4 MICRO (Waters). Analyses were run on a ACQUITY BEH Phenyl (ABP) $(50$ X 2.1 mm, $1.7 \mu \mathrm{m})$ or ACQUITY BEH Shield (ABS) $(100 \times 2.1 \mathrm{~mm}, 1.7 \mu \mathrm{m})$ columns, at room temperature, with gradient elution (solvent $\mathrm{A}$ : water containing $0.1 \%$ of formic acid; solvent $\mathrm{B}$ : methanol containing $0.1 \%$ of formic acid; gradient: $10 \% \mathrm{~B}$ in A to $100 \% \mathrm{~B}$ in $3 \mathrm{~min}$, followed by isocratic elution $100 \% \mathrm{~B}$ for $1.5 \mathrm{~min}$, return to the initial conditions in $0.2 \mathrm{~min}$ ) at a flow rate of $0.5 \mathrm{~mL} \mathrm{~min}-1$. All the final compounds had $95 \%$ or greater purity. 


\subsubsection{Compound synthesis}

Racemic and enantiomeric RC-33 have been re-synthetized according to the already published procedures $[22,44]$. These are summarized in Scheme 1.

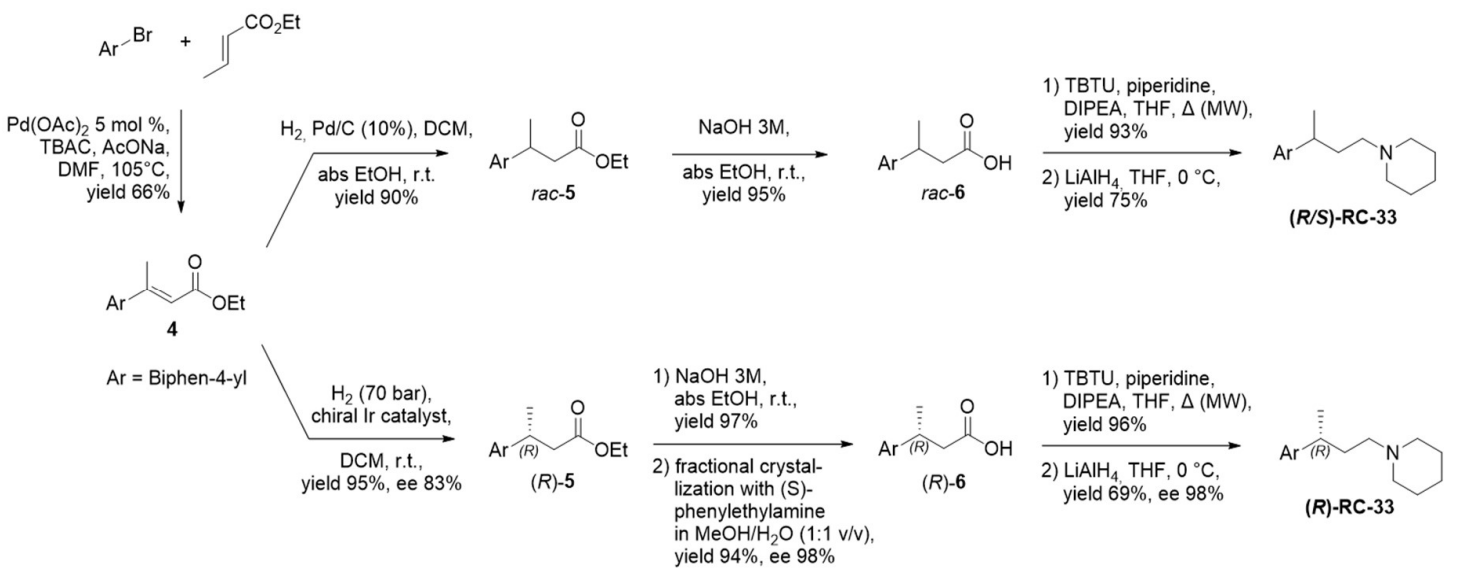

Scheme 1. Schematic synthesis procedures of racemic and enantiomeric RC-33.

Briefly, a Heck reaction between 4-Bromobiphenyl and ethyl crotonate was performed to access $\alpha, \beta$-unsaturated ester 4 . This was subjected to a reduction of the double bond, performed either without stereocontrol $\left(\mathrm{H}_{2}\right.$ gas in presence of $\left.\mathrm{Pd} / \mathrm{C}\right)$ or under enantioselective conditions $\left(\mathrm{H}_{2}\right.$ gas in presence of a chiral Ir catalyst), to access racemic 5 and $(R)-5$ respectively. Ester hydrolysis afforded acid 6, which could be subjected to fractional crystallization to enhance the enantiomeric excess in the synthesis of enantiopure RC-33. Acid 6 was then subjected to amidation with piperidine in the presence of condensing agent TBTU. Afterwards, reduction of the amide moiety with $\mathrm{LiAlH}_{4}$ afforded RC-33 either in racemic or enantiopure form (ee 98\%). The identity of obtained products was confirmed by ${ }^{1} \mathrm{H}$ - and ${ }^{13} \mathrm{C}-\mathrm{NMR}$, whereas optical purity was assessed by chiral-HPLC following the method developed in our lab. Overall, the analyses resulted consistent with published data [22, $44]$.

Compounds 1-3 were prepared following the procedure reported in our previous publication, with slight modifications [26]. Overall, the synthetic strategy is based on the Weinreb ketone synthesis, as shown in Scheme 2.


Scheme 2. Schematic synthesis procedures of compounds 1-3.

Briefly, Weinreb amides I-II were either purchased if commercially available (amide I) or prepared by reacting the corresponding acyl chloride with $\mathrm{N}, \mathrm{O}$-dimethylhydroxyamine hydrochloride. Afterwards, nucleophilic substitution on Weinreb amides I-II was carried out using 
amines a-b. This led to the key intermediates Ia-IIb. Finally, compounds 1-3 were obtained by coupling intermediates Ia-IIb with different aryl lithium species generated in situ. Aromatic moieties thus introduced are naphth-2-yl and 4-biphenyl. This last step involves the smooth bromo-lithium exchange on the aryl bromide to access the lithiated arene that, after addition of Weinreb amides IaIIb and quenching with $\mathrm{H}_{2} \mathrm{O}$ gave the desired crude ketones 1-3 in good yields. After flash chromatography purification, compounds were converted into their corresponding hydrochlorides by addition of $\mathrm{HCl}$ in $\mathrm{Et}_{2} \mathrm{O}$. The identity of obtained products was confirmed by ${ }^{1} \mathrm{H}$ - and ${ }^{13} \mathrm{C}-\mathrm{NMR}$ and the analyses resulted consistent with published data [26].

\subsection{Cell culture}

HeLa cells were grown in plastic tissue culture flasks using Dulbecco's modified minimal essential medium high glucose, supplemented with $10 \%$ fetal bovine serum, $1 \%$ L-glutamine, $1 \%$ penicillin and streptomycin and maintained at $37^{\circ} \mathrm{C}$ in a humidified atmosphere of $5 \% \mathrm{CO}, 95 \%$ air.

\subsection{Water permeability measurements}

Osmotic water permeability was measured in HeLa cells suspension by the stopped-flow light scattering method as previously described [17]. The experiments were performed at $25^{\circ} \mathrm{C}$ on a stopped flow apparatus (RX2000, Applied Photophysics, Leatherhead, UK) with a pneumatic drive accessory (DA.1, Applied Photophysics) straightforward coupled with a Varian Cary 50 spectrometer (Varian Australia Pty Ltd, Australia). Scattered light intensity with a dead time of $6 \mathrm{~ms}$ was recorded at a wavelength of $450 \mathrm{~nm}$. The time course of cell swelling caused by exposure to the hypotonic gradient $(150 \mathrm{mosm} / \mathrm{L})$ was measured for $60 \mathrm{~s}$ at the acquisition rate of one point $/ 0.0125 \mathrm{~s}$. The initial rate constant of cell volume changes $(\mathrm{k})$ was obtained by setting the time course light scattering with a single exponential equation (GraphPad Prism 4.00, 2003).

To evaluate the antioxidant effect of the test compounds on water permeability HeLa cells were divided into different groups: (1) controls, cells left at room temperature $\left(21^{\circ} \mathrm{C}\right)$; (2) heat-stressed cells, cells subjected to heat-treatment by placing them in a water thermostatic and shacking bath $42^{\circ} \mathrm{C}$ for $3 \mathrm{~h}$; (3) heat-stressed cells pre-treated, cells heat-stressed with the antioxidants compounds at 20 $\mu \mathrm{M}$ final concentration (dissolved in methanol). Moreover, to test the possible capacity of the molecules to affect the AQP gating in eustress condition, HeLa cells were treated in the presence and in the absence of the compounds by incubating at $21^{\circ} \mathrm{C}$ for $3 \mathrm{~h}$.

\subsection{Hydrogen peroxide permeability measurements}

Dose-response relationship was assessed for PV410 and PV411 compounds by measuring the hydrogen peroxide concentrations in heat-stressed HeLa cells. Hydrogen peroxide levels were measured by a fluorescence method using the 5-(and-6)-chloromethyl-20,70-dichlorodihydrofluorescein diacetate, acetyl ester reagent (CM-H2DCFDA) (Thermo Fisher Scientific Inc., Italy) as previously described [17]. Briefly, cells were centrifuged at $200 \mathrm{rcf}$ for $5 \mathrm{~min}$. The cell pellet was resuspended in PBS with increasing concentrations of the compounds 1 and $2(0,5,10,20,40 \mu \mathrm{M}$ final concentration) and subjected to heat-stress as above indicated. Before terminating the incubation, the CM-H2DCFDA reagent was added at $10 \mu \mathrm{M}$ final concentration and leaved for further $15 \mathrm{~min}$ at $42^{\circ} \mathrm{C}$. Then, cells were centrifuged, and the pellet resuspended in PBS. Hydrogen peroxide levels were measured by using a CLARIOstar ${ }^{\circledR}$ microplate reader (BMG LABTECH, Ortenberg, Germany). Values are expressed as arbitrary unit per mg total protein.

\subsection{Gene silencing}

S1R knockdown was performed by treating HeLa cells with ON-TARGETplus SMARTpool Human SIGMAR1 siRNA (FE5LHUMANXX0005; Carlo Erba Reagents Srl, Italy) at a $25 \mathrm{nM}$ final concentration. Negative controls were done with scrambled siRNA. siRNAs were diluted in siRNA 
Diluition Buffer (N0413, Sigma-Aldrich, USA) and mixed with N-TER peptide (N2788, SigmaAldrich, USA) pre-diluted in PBS, according to the manufacturer's instructions to create the Target siRNA Nanoparticle Formation Solution (NFS). HeLa cells at 50\% confluence were removed from the medium and replaced with fresh medium containing NFS. After $30 \mathrm{~min}$ incubation at $37^{\circ} \mathrm{C}$, the NFS was diluted in the culture medium and added to the cells and incubated at $37^{\circ} \mathrm{C}$ for $24 \mathrm{~h}$.

Immunoblotting was used to validate the gene silencing and the silenced cells were used 24 hours after transfection.

\subsection{Immunoblotting}

Cells were homogenized with a Dounce homogenizer in RIPA buffer $(150 \mathrm{mM} \mathrm{NaCl}, 0.5 \%$ sodium deoxycholate, $0.1 \%$ SDS, $0.1 \%$ Triton $\mathrm{X}-100,50 \mathrm{mM}$ Tris- $\mathrm{HCl}, \mathrm{pH}$ 8) supplemented with a protease inhibitor cocktail (cOmplete Tablets EASYpack, 04693116001, Roche, Germany).

Immunoblotting was carried out as previously described [45] loading $30 \mu \mathrm{g}$ proteins. Membranes were incubated overnight with anti-Sigma1 Receptor (B-5) (sc-137075, 1:500 dilution; Santa Cruz Biotechnology, Inc., USA) in a blocking solution (Tris buffered saline, 5\% skimmed dry milk and $0.1 \%$ Tween). The membranes were washed thrice and incubated for $1 \mathrm{~h}$ with peroxidaseconjugated rabbit anti-mouse IgG (Dakocytomation, P0260, Agilent, Italy), diluted 1:120000 in blocking solution. The bands were detected with Westar Supernova western blotting detection system (CYANAGEN) and pre-stained molecular weight markers (ab116028, Abcam) used to calculate the molecular weights of the bands.

Blots were stripped following Yeung and Stanley [46] and reprobed with anti $\beta$-2-microglobulin (B2M) rabbit antibody (ab75853, Abcam, Cambridge, UK) diluted 1:10000 in blocking solution.

Densitometry was performed by acquiring the blots with the iBrightTM CL1000 Imaging System (Thermo Fisher Scientific Inc., USA). The semiquantitation of the bands was performed using the iBA (iBright Analysis Software; Thermo Fisher Scientific Inc., Italy) and the results were expressed as S1R/B2M ratio.

\subsection{Protein content}

The protein content was determined with the Bradford method [47], using bovine serum albumin as standard.

\subsection{Statistics}

All data were expressed as mean \pm S.E.M. The significance of the differences of the means was evaluated by using repeated measures one-way ANOVA followed by Newman-Keuls's $Q$ test. All statistical tests were carried out using GraphPad Prism 4.00, 2003.

\section{Results}

For evaluating water and hydrogen peroxide permeability in HeLa cells, in this study we used a cheap, very sensitive and reproducible method based on stopped-flow light scattering. A first set of experiments has been performed, using well characterized S1R modulators, the S1R antagonist NE-100 and the S1R agonists PRE-084 and RC-33 (racemic and (R)-configured). Results reported in Figure 2 clearly evidenced a different behavior of S1R modulators, depending on their agonist/antagonist profile. Heat-stress reduced the water permeability and the pre-treatment with PRE-084 and racemic RC-33 $(20 \mu \mathrm{M})$ restored water permeability in heat-stressed cells, whereas the Sigma-1 antagonist NE-100 was unable to counteract oxidative stress conditions (Figure 2A). Conversely, the treatment of cells under normal conditions (incubation in the absence of heat-stress) with the S1R modulators had no effect on water permeability (Figure 2B). Moreover, NE-100 $(20 \mu \mathrm{M})$, co-administered with $(R / S)$-RC-33 totally counteracted its ability to prevent or restore the water 
permeability decrease in heat-stressed cells, confirming that S1R agonists are involved in modulation of water and hydrogen peroxide permeability in Hela cells (Figure 3).
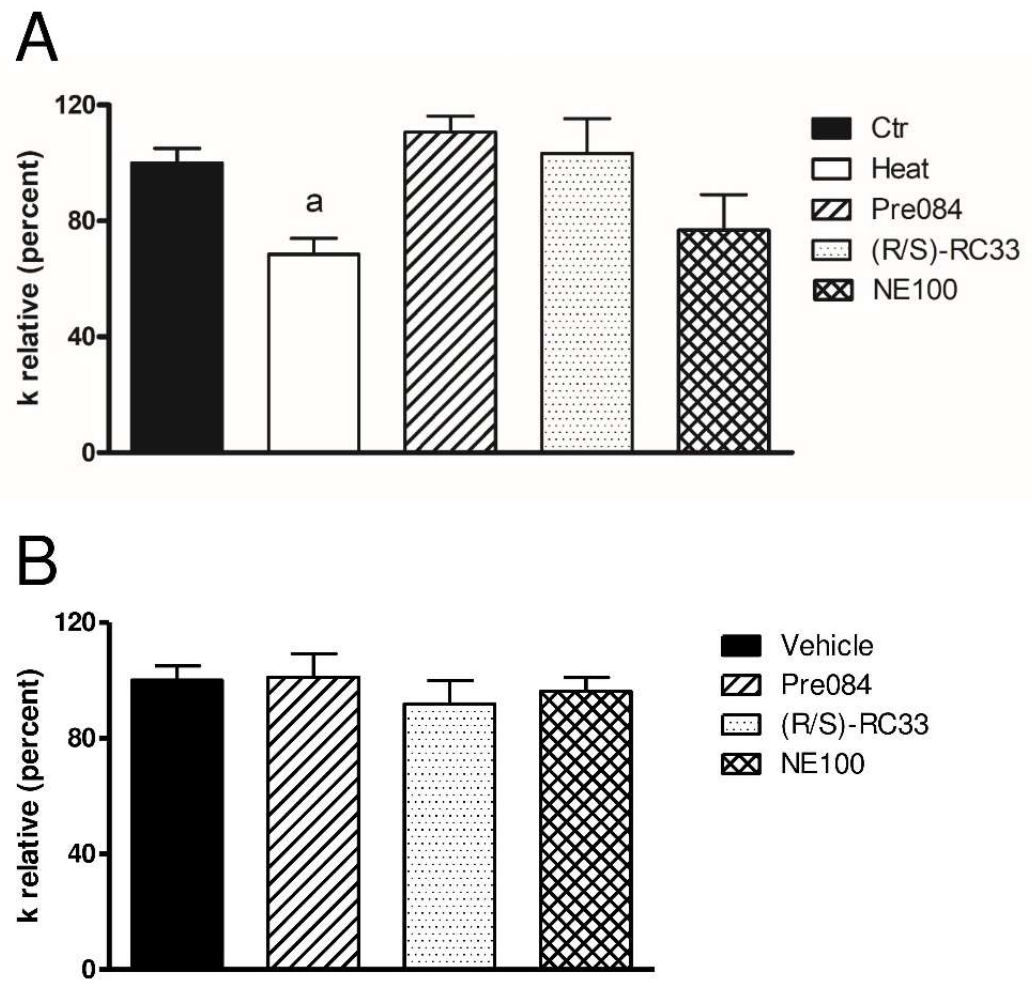

Figure 2. Effect of S1R modulators on the water permeability of HeLa cells in heat-stress conditions (A) and in normal non-stressed conditions (B). Bars represent the osmotic water permeability of HeLa cells expressed as percent of $\mathrm{k}$ relative. Values are means \pm SEM of 4-15 single shots (time course curves) for each of 4-6 different experiments. (A) HeLa cells were exposed to a 150 mOsm osmotic gradient in different conditions: untreated cells (Controls, Ctr); cells treated at $42^{\circ} \mathrm{C}$ for $3 \mathrm{~h}$ (heatstressed, Heat); heat-stressed cells pre-treated with test compounds (Pre084, (R/S)-RC-33 and NE-100) at $20 \mu \mathrm{M}$ final concentration. (B) Hela cells were incubated at $21^{\circ} \mathrm{C}$ for $3 \mathrm{~h}$ with the compounds at 20 $\mu \mathrm{M}$ final concentration and, successively, were exposed to a $150 \mathrm{mOsm}$ osmotic gradient. Vehicle indicates cells incubated without compounds. a, $\mathrm{P}<0.05$ vs. Ctr, Pre084, (R/S)-RC-33 (Repeated measures ANOVA, followed by Newman-Keuls's Q test).

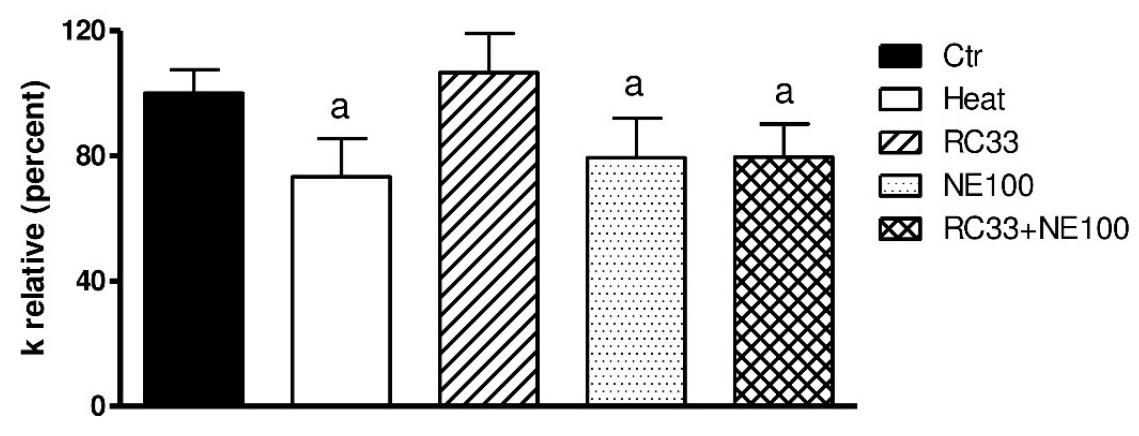

Figure 3. Effect of the NE-100 and $(R / S)$-RC-33 co-administration on the water permeability of HeLa cells in heat-stress condition. Comparison between untreated cells (Controls, Ctr), cells treated at $42^{\circ} \mathrm{C}$ for $3 \mathrm{~h}$ (heat-stressed, Heat), heat-stressed cells pre-treated separately with NE-100 and (R/S)-RC-33 at $20 \mu \mathrm{M}$ and heat-stressed cells pre-treated simultaneously with NE-100 and (R/S)-RC-33. Bars 
represent the osmotic water permeability of HeLa cells expressed as percent of $k$ relative. Values are means \pm SEM of 4-15 single shots (time course curves) for each of 4-6 different experiments. a, $\mathrm{P}<0.05$ vs. Ctr, (R/S)-RC-33 (Repeated measures ANOVA, followed by Newman-Keuls's Q test).

As a further confirmation, we probed whether RC-33 stereochemistry plays a role in the modulation of AQPs. Our previous studies demonstrated that the racemic RC-33 and both $(R)$ and $(S)$ enantiomers show nearly the same affinity toward the binding site of S1R and are equally effective in promoting neurite outgrowth in PC12 cellular model. Subsequent investigations demonstrated that $(R)-R C-33$ is endowed with higher in vitro metabolic stability, and for this reason was selected as the eutomer for further in vivo studies [48]. Here, we compared the effect of $(R / S)$-RC-33 with that of $(R)$-RC-33. Racemic and $(R)$-configured RC-33 showed a similar behavior in the experiments on water permeability (Figure 4 ).



Figure 4. Effect of the RC-33 stereochemistry on the water permeability of HeLa cells in heat-stress condition. Comparison between untreated cells (Controls, Ctr), cells treated at $42^{\circ} \mathrm{C}$ for $3 \mathrm{~h}$ (heatstressed, Heat), heat-stressed cells pre-treated with racemic $(R / S)-R C 33$ and enantiopure $(R)-R C-33$ at $20 \mu \mathrm{M}$ final concentration. Bars represent the osmotic water permeability of HeLa cells expressed as percent of k relative. Values are means \pm SEM of 4-15 single shots (time course curves) for each of 4-6 different experiments. a, $\mathrm{P}<0.05$ vs. Ctr, $(R / S)$-RC33, $(R)-$ RC-33 (Repeated measures ANOVA, followed by Newman-Keuls's $Q$ test).

We extended the investigation to compounds 1-3, belonging to a library of aryl aminoalkyl ketones with S1R binding affinity and antioxidant properties [26]. Heat-stressed cells treated with compounds 1-3 displayed a restored water permeability (Figure 5A). HeLa cells treated with compound $\mathbf{3}$ had a significantly higher water permeability than those incubated with compound $\mathbf{2}$ (Figure 5A). The behavior is superimposable with that of well-established S1R agonists PRE-084 and RC-33. On the other hand, the treatment of the cells with our test compounds under normal conditions had no effect on water permeability (Figure 5B).

Moreover, we established the dose-response relationship for compounds 2 and 3 and the $\mathrm{H}_{2} \mathrm{O}_{2}$ content within the cell (Figure 6). Results showed that these molecules are effective in reduction of $\mathrm{H}_{2} \mathrm{O}_{2}$ levels within the cell in a dose-dependent fashion. However, the compounds had similar response per unit dose since the slopes of the lines did not statistically differed (compound 2: 56.98 \pm 4.7; compound 3: $-48.00 \pm 13.0 ; \mathrm{P}=0.54$, Student's t test).

To understand if S1R modulators could have also an AQP effect, experiments were made using HeLa cells selectively knocked down for S1R. Short interfering RNAs (siRNAs) targeting human S1R were used. The effectiveness in silencing was assessed by immunoblotting. Figure 7A and B showed that S1R protein was significantly knocked-down of about 50\% compared to controls. Successively, silenced HeLa cells were heat-stressed in the presence and in the absence of S1R agonists and the water permeability measured. The water permeability of controls and heat-stressed cells did not differ, thus demonstrating that S1R depletion induced an oxidative stress even in the absence of heat treatment (Figure 7C). Heat treatment of the S1R-null cells in the presence of Pre084, 1, 2 and 3 
increased the water permeability from 38 to $58 \%$ (Figure 7C). This result demonstrates that the aboveindicated compounds were able to counteract the oxidative stress by interacting with both S1R and AQPs. On the contrary, pre-treatment of the cells with RC-33 did not significantly modify the water permeability, suggesting an exclusive activity of RC-33 on S1R.


Figure 5. Effect of compounds 1- 3 on the water permeability of HeLa cells in heat-stress condition (A) and in normal non-stressed condition (B). (A) Comparison between untreated cells (Controls, Ctr), cells treated at $42^{\circ} \mathrm{C}$ for $3 \mathrm{~h}$ (heat-stressed, Heat), heat-stressed cells pre-treated with test compounds at $20 \mu \mathrm{M}$ final concentration. (B) Effect of the compounds on water permeability of Hela cells incubated at $21^{\circ} \mathrm{C}$ for $3 \mathrm{~h}$. Vehicle indicates cells incubated without compounds. Bars represent the osmotic water permeability of HeLa cells expressed as percent of $k$ relative. Values are means \pm SEM of 4-15 single shots (time course curves) for each of 4-6 different experiments. a, $\mathrm{P}<0.01$ vs. Ctr, $1,2,3 ; \mathrm{b}, \mathrm{P}<0.05$ vs. 3 (Repeated measures ANOVA, followed by Newman-Keuls's $Q$ test). 

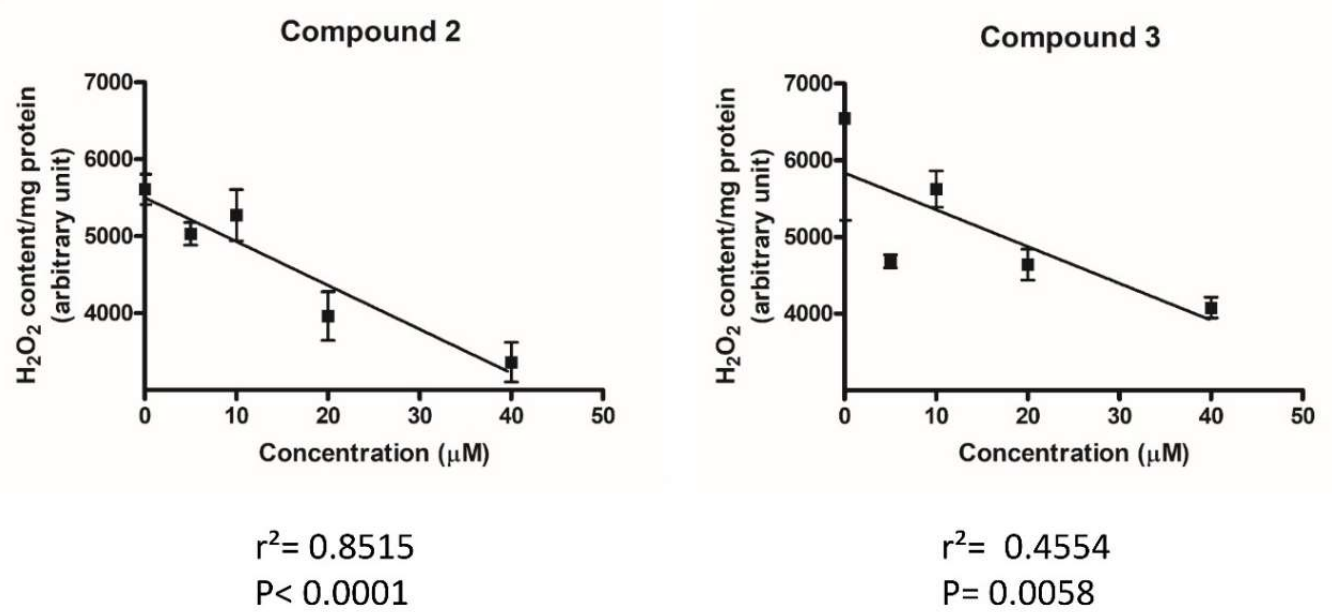

Figure 6. Dose-response effect of compounds 2 and 3 on HeLa cells $\mathrm{H}_{2} \mathrm{O}_{2}$ content. HeLa cells were heat-stressed at $42^{\circ} \mathrm{C}$ for $3 \mathrm{~h}$ and pre-treated with increasing concentrations of test compounds. $\mathrm{H}_{2} \mathrm{O}_{2}$ was measured using the CM-H2DCFDA reagent (see Materials and methods). Values represent mean \pm SEM $(n=4)$ and are expressed as $\mathrm{H}_{2} \mathrm{O}_{2}$ content (arbitrary unit) per mg protein. Overall, linear regression (black line) is presented. $\mathrm{P}$ and $\mathrm{r}^{2}$ values are shown.
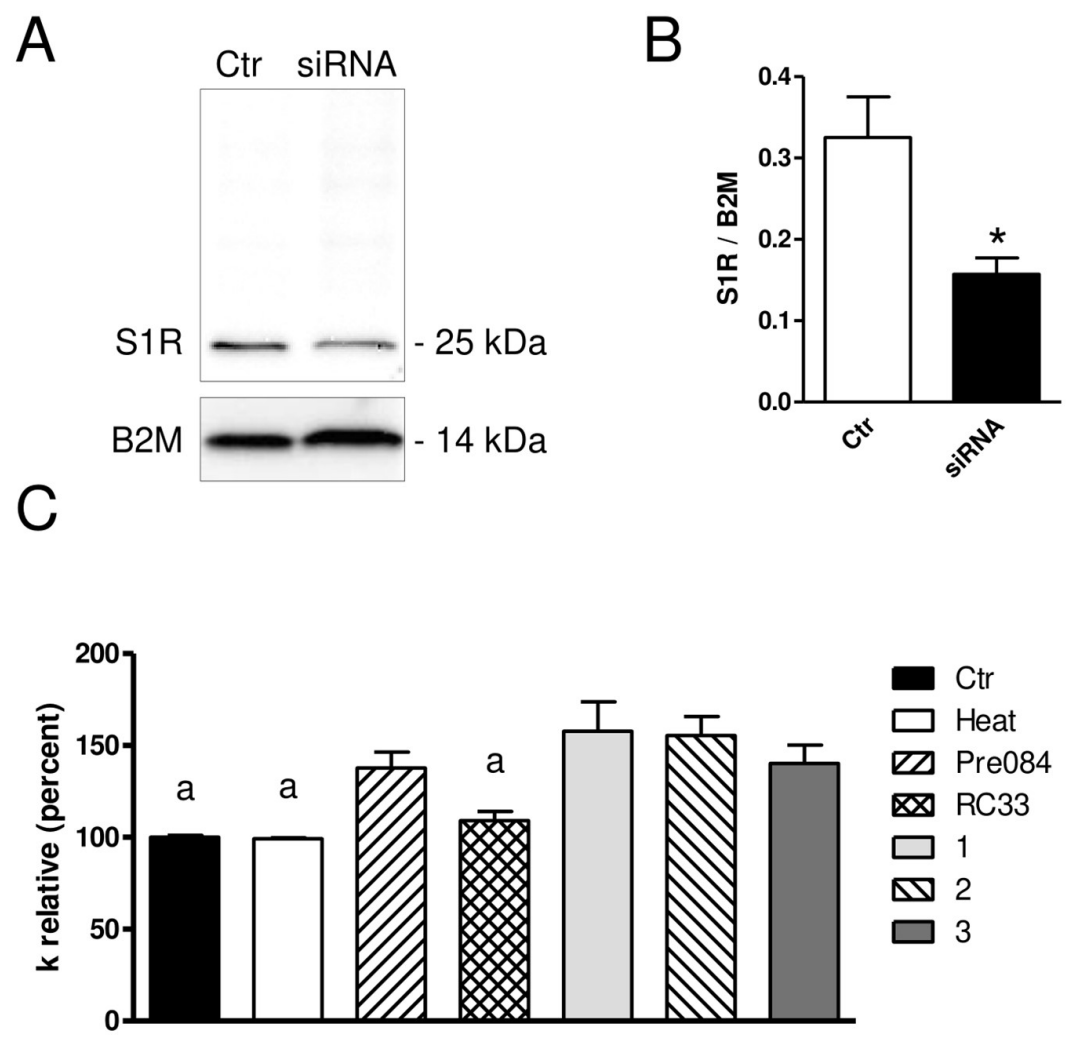

Figure 7. S1R silencing in HeLa cells. HeLa cells were silenced and the effectiveness in silencing was tested by immunoblotting and densitometry demonstrating a significant reduced protein expression in silenced (siRNA) cells compared to controls (scrambled; Ctr) $\left(^{*}, \mathrm{P}<0.001\right.$; Student's $t$ test). (A) A representative blot is shown. $30 \mu \mathrm{g}$ of proteins were loaded and the blots incubated with anti-S1R 
antibody. Blots were stripped and re-probed with anti $\beta$-2-microglobulin (B2M) antibody. Bands of 25 and $14 \mathrm{kDa}$ were obtained for S1R and B2M, respectively. (B) Densitometry was performed by acquiring the blot with the iBright CL1000 imaging system. Semiquantitation was performed by iBA (iBright Analysis Software) and the results were normalized to the corresponding B2M. (C) Effect of S1R agonist treatment on the water permeability of S1R-null HeLa cells heat-stressed (Heat). The compounds were used at $20 \mu \mathrm{M}$ final concentration. Ctr, control, untreated HeLa cells silenced for S1R. a, $\mathrm{P}<0.05$ vs. Pre084, 1, 2, 3 (ANOVA, followed by Newman-Keuls's Q test).

\section{Discussion}

In the first set of experiments, we evaluated the effect of the well characterized S1R agonists PRE-084 and racemic RC-33 in HeLa cells, and we compared the results with the known S1R antagonist NE-100. All compounds were tested in the presence and in absence of oxidative stress conditions. Heat shock was used as a cell stressor, and the resulting variation in osmotic water permeability was measured by a stopped-flow light scattering method, which has the advantages of high sensitivity, good reproducibility and cost-effectiveness. We observed that all compounds had no effect on water permeability under normal conditions (non-stressed cells). It can be assumed that the compounds can act on AQPs only in the "oxidized" form. In our previous study, we have demonstrated that some antioxidant compounds were able to protect (pre-treatment) or reverse (post-treatment) the water permeability of HeLa cells heat-stressed [17]. Particularly, curcumin was the only compound showing a different behavior, inhibiting the water permeability in the absence of oxidative stress [17]. Conversely, two distinct profiles could be drawn under oxidative stress: S1R agonists PRE-084 and RC-33 were able to restore water permeability, whereas NE-100 was ineffective. The subsequent co-administration of RC-33 and NE-100 to heat-stressed cells, evidenced that the effect of the antagonist quenched the antioxidant properties of the agonist, confirming that the effect appears S1R mediated. Moreover, the effects of racemic RC-33 and of $(R)$-RC-33 are superimposable, as expected by their S1R binding profile. Next, extended our investigation on the S1R ligands 1-3. It is worth noting that compounds 1-3 were originally designed by merging the pharmacophoric elements of different neuroprotective and/or antioxidant molecules, including the already mentioned curcumin. Compound 1 possesses a good binding profile, a free radical scavenging activity in the 2,2diphenyl-1-picrylhydrazyl (DPPH) assay and it is able to reduce ROS in SH-SY5Y cells, after an exposure to oxidative damages mediated by $\mathrm{H}_{2} \mathrm{O}_{2}$, in the $2^{\prime}, 7^{\prime}$-dichlorofluorescein diacetate assay. Compounds 2 and 3 showed a better binding affinity toward S1R, but a lower antioxidant profile. Therefore, with the aim to evaluate the antioxidant profile of our developed compounds with different orthogonal assays, and on the wave of the results obtained in the present study, we tested the effect of compounds 1-3 on HeLa cells under both normal conditions and oxidative stress. Compounds 1-3 resulted able to protect the water permeability in heat-stressed cells like RC-33 and PRE-084 that do not display any intrinsic antioxidant activity as observed in DPPH assay [26]. Although compounds 1-3 possess the pharmacophoric elements of curcumin, they show a different behavior, since they do not inhibit the water permeability in the absence of oxidative stress, thus suggesting a successful optimization of the biological profile.

A dose-response correlation has been determined for the best performing compounds, 2 and 3 , assessing the cellular $\mathrm{H}_{2} \mathrm{O}_{2}$ content. Based on results obtained (Figure 6) and since both compounds (2 and 3) displayed poor free radical scavenging activity in the DPPH assay, we can conclude that antioxidant activity might be mainly AQP-mediated and that there is a correlation between S1R and AQP modulation.

However, the possibility that the compounds could act on S1R and that the restoring effect on osmotic permeability was indirect could not be ruled out. To discriminate the effect on the two targets we performed experiments in HeLa cells knocked down for S1R. The results clearly showed that RC33 is unable to recover S1R-depleted cells from oxidative stress and thus it acts only through S1R modulation. Conversely, Pre084, 1, 2 and 3 are able also to increase ROS scavenging thereby protecting the cells from oxidative stress damage. Therefore, compounds 1-3 exert their activity on 
both S1R and AQP. They are the first members of a new series of dual modulators of AQP and S1R, by now called DAS 1-3.

\section{Conclusions}

Overall, our study indicates that the investigated S1R agonists showed antioxidant properties through a double mechanism: the interaction with S1R and the direct modulation of AQP, with the only exception of the S1R agonist RC-33. Although S1R are undoubtedly involved in the oxidative stress process, the roles of S1R are not completely understood and thus results herein presented add a piece to the complex puzzle of S1R. S1R has been extensively studied in the past decades, and its modulators have been proposed as viable tools for different therapeutic applications, reaching advanced stages of drug development (e.g. MR309, a Sigma-1 antagonist is currently in Phase II clinical trial for the treatment of neuropathic pain) $[31,49,50]$. On the other hand, aquaporins are still largely unexplored from a medicinal chemistry standpoint and have been recognized as druggable molecular targets only recently [17, 51-55]. To the best of our knowledge, this represents the first report involving modulators of both AQP and S1R. Results herein presented support the hypothesis that drug-like small molecules can modulate AQPs. The mutual correlation of AQPs and S1R opens a new avenue for the development of new bioactive molecules with synergistic activities. In fact, oxidative stress is a typical condition in debilitating pathologies where S1R is involved, namely neurodegenerative diseases and cancer. DAS 1-3 represent the first members of a new class of AQP and S1R modulators. Further research on such small molecules is warranted to create an opportunity to develop novel therapies to treat diseases involving oxidative stress.

Author Contributions: Conceptualization, U.L., S.C.; Formal Analysis, U.L., G.P., D.R.; Investigation, G.P., G.R.; Resources, U.L., G.G.; Data Curation, U.L., G.P., G.R., P.L.; Writing-Original Draft Preparation, U.L., S.C.; Visualization, G.P., U.L., D.R., P.L.; Supervision, U.L., S.C.; Funding Acquisition, U.L., G.G., S.C..

Funding: This research was funded by the Department of Molecular Medicine of the University of Pavia, Italy under the initiative Dipartimenti di Eccellenza (2018-2022).

Acknowledgments: Graphical abstract was created by BioRender.com.

Conflicts of Interest: The authors declare no conflict of interest.

\section{Abbreviations}

ROS: reactive oxygen species

AQP: aquaporin

S1R: Sigma1 Receptor

ER: endoplasmic reticulum

CM-H2DCFDA: 5-(and-6)-chloromethyl-2',7'-dichlorodihydrofluorescein diacetate, acetyl ester

siRNA: Short interfering RNA

DPPH : 2,2-diphenyl-1-picrylhydrazyl (

\section{References}

1. Bienert, G.P.; Schjoerring, J.K.; Jahn, T.P. Membrane transport of hydrogen peroxide. Biochim Biophys Acta 2006, 1758(8), 994-1003.

2. Veal, E.A.; Day, A.M.; Morgan, B.A. Hydrogen peroxide sensing and signaling. Mol Cell 2007, 26(1), 1-14.

3. Bienert, G.P.; Chaumont, F. Aquaporin-facilitated transmembrane diffusion of hydrogen peroxide. Biochim Biophys Acta 2014, 1840(5), 1596-1604.

4. Medraño-Fernandez, I.; Bestetti, S.; Bertolotti, M.; Bienert, G.P.; Bottino, C.; Laforenza, U.; Rubartelli, A.; Sitia, R. Stress Regulates Aquaporin-8 Permeability to Impact Cell Growth and Survival. Antioxid Redox Signal 2016, 24(18), 1031-1044.

5. Zuo, L.; Zhou, T.; Pannell, B.K.; Ziegler, A.C.; Best, T.M. Biological and physiological role of reactive oxygen species--the good, the bad and the ugly. Acta Physiol (Oxf) 2015, 214(3), 329-348. 
6. Tamma, G.; Valenti, G.; Grossini, E.; Donnini, S.; Marino, A.; Marinelli, R.A.; Calamita, G. Aquaporin Membrane Channels in Oxidative Stress, Cell Signaling, and Aging: Recent Advances and Research Trends. Oxid Med Cell Longev 2018, 2018, 1501847.

7. Bienert, G.P.; Møller, A.L.; Kristiansen, K.A.; Schulz, A.; Møller, I.M.; Schjoerring, J.K.; Jahn, T.P. Specific aquaporins facilitate the diffusion of hydrogen peroxide across membranes. J Biol Chem 2007, 282(2), 11831192.

8. Hara-Chikuma, M.; Watanabe, S.; Satooka, H. Involvement of aquaporin-3 in epidermal growth factor receptor signaling via hydrogen peroxide transport in cancer cells. Biochem Biophys Res Commun 2016, 471(4), 603-609.

9. Miller, E.W.; Dickinson, B.C.; Chang, C.J. Aquaporin-3 mediates hydrogen peroxide uptake to regulate downstream intracellular signaling. Proc Natl Acad Sci U S A 2010, 107(36), 15681-15686.

10. Hara-Chikuma, M.; Chikuma, S.; Sugiyama, Y.; Kabashima, K.; Verkman, A.S.; Inoue, S.; Miyachi, Y. Chemokine-dependent $\mathrm{T}$ cell migration requires aquaporin-3-mediated hydrogen peroxide uptake. J Exp Med 2012, 209(10), 1743-1752.

11. Thiagarajah, J.; Zhao, D.; Verkman, A. Impaired enterocyte proliferation in aquaporin-3 deficiency in mouse models of colitis. Gut 2007, 56(11), 1529-1535.

12. Rodrigues, C.; Mósca, A.F.; Martins, A.P.; Nobre, T.; Prista, C.; Antunes, F.; Cipak Gasparovic, A.; Soveral, G. Rat Aquaporin-5 Is $\mathrm{pH}$-Gated Induced by Phosphorylation and Is Implicated in Oxidative Stress. Int J Mol Sci 2016, 17(12), 2090.

13. Bertolotti, M.; Bestetti, S.; García-Manteiga, J.M.; Medraño-Fernandez, I.; Dal Mas, A.; Malosio, M.L.; Sitia, R. Tyrosine kinase signal modulation: a matter of $\mathrm{H}_{2} \mathrm{O}_{2}$ membrane permeability? Antioxid Redox Signal 2013, 19(13), 1447-1451.

14. Watanabe, S.; Moniaga, C.S.; Nielsen, S.; Hara-Chikuma, M. Aquaporin-9 facilitates membrane transport of hydrogen peroxide in mammalian cells. Biochem Biophys Res Commun 2016, 471(1), 191-197.

15. Bestetti, S.; Galli, M.; Sorrentino, I.; Pinton, P.; Rimessi, A.; Sitia, R.; Medraño-Fernandez, I. Human aquaporin-11 guarantees efficient transport of $\mathrm{H}_{2} \mathrm{O}_{2}$ across the endoplasmic reticulum membrane. Redox Biol 2020, 28, 101326.

16. Laforenza, U.; Pellavio, G.; Marchetti, A.L.; Omes, C.; Todaro, F.; Gastaldi, G. Aquaporin-Mediated Water and Hydrogen Peroxide Transport Is Involved in Normal Human Spermatozoa Functioning. Int J Mol Sci 2016, 18(1), 66.

17. Pellavio, G.; Rui, M.; Caliogna, L.; Martino, E.; Gastaldi, G.; Collina, S.; Laforenza, U. Regulation of Aquaporin Functional Properties Mediated by the Antioxidant Effects of Natural Compounds. Int J Mol Sci 2017, 18(12), 2665.

18. Pellavio, G.; Todaro, F.; Alberizz, P.; Scotti, C.; Gastaldi, G.; Lolicato, M.; Omes, C.; Caliogna, L.; Nappi, R.E.; Laforenza, U. HPV Infection Affects Human Sperm Functionality by Inhibition of Aquaporin-8. Cells 2020, 9(5), 1241.

19. Thanan, R.; Oikawa, S.; Hiraku, Y.; Ohnishi, S.; Ma, N.; Pinlaor, S.; Yongvanit, P.; Kawanishi, S.; Murata, M. Oxidative stress and its significant roles in neurodegenerative diseases and cancer. Int J Mol Sci 2014, 16(1), 193-217.

20. Uttara, B.; Singh, A.V.; Zamboni, P.; Mahajan, R.T. Oxidative stress and neurodegenerative diseases: a review of upstream and downstream antioxidant therapeutic options. Curr Neuropharmacol 2009, 7(1), 6574.

21. Vigani, B.; Rossi, S.; Sandri, G.; Bonferoni, M.C.; Rui, M.; Collina, S.; Fagiani, F.; Lanni, C.; Ferrari, F. DualFunctioning Scaffolds for the Treatment of Spinal Cord Injury: Alginate Nanofibers Loaded with the Sigma 1 Receptor (S1R) Agonist RC-33 in Chitosan Films. Mar Drugs 2019, 18(1), 21.

22. Marra, A.; Rossi, D.; Pignataro, L.; Bigogno, C.; Canta, A.; Oggioni, N.; Malacrida, A.; Corbo, M.; Cavaletti, G.; Peviani, M.; Curti, D.; Dondio, G.; Collina, S. Toward the identification of neuroprotective agents: gscale synthesis, pharmacokinetic evaluation and CNS distribution of (R)-RC-33, a promising SIGMA1 receptor agonist. Future Med Chem 2016, 8(3), 287-295.

23. Rui, M.; Rossi, D.; Marra, A.; Paolillo, M.; Schinelli, S.; Curti, D.; Tesei, A.; Cortesi, M.; Zamagni, A.; Laurini, E.; Pricl, S.; Schepmann, D.; Wünsch, B.; Urban, E.; Pace, V.; Collina, S. Synthesis and biological evaluation of new aryl-alkyl(alkenyl)-4-benzylpiperidines, novel Sigma Receptor (SR) modulators, as potential anticancer-agents. Eur J Med Chem 2016, 124, 649-665.

24. Rossi, D.; Urbano, M.; Pedrali, A.; Serra, M.; Zampieri, D.; Mamolo, M.G.; Laggner, C.; Zanette, C.; Florio, C.; Schepmann, D.; Wuensch, B.; Azzolina, O.; Collina, S. Design, synthesis and SAR analysis of novel selective sigma1 ligands (Part 2). Bioorg Med Chem 2010, 18(3), 1204-1212. 
25. Collina, S.; Loddo, G.; Urbano, M.; Linati, L.; Callegari, A.; Ortuso, F.; Alcaro, S.; Laggner, C.; Langer, T.; Prezzavento, O.; Ronsisvalle, G.; Azzolina, O. Design, synthesis, and SAR analysis of novel selective sigma1 ligands. Bioorg Med Chem 2007, 15(2), 771-783.

26. Rui, M.; Rossino, G.; Coniglio, S.; Monteleone, S.; Scuteri, A.; Malacrida, A.; Rossi, D.; Catenacci, L.; Sorrenti, M.; Paolillo, M.; Curti, D.; Venturini, L.; Schepmann, D.; Wünsch, B.; Liedl, K.R.; Cavaletti, G.; Pace, V.; Urban, E.; Collina, S. Identification of dual Sigma1 receptor modulators/acetylcholinesterase inhibitors with antioxidant and neurotrophic properties, as neuroprotective agents. Eur J Med Chem 2018, 158, 353370.

27. Franchini, S.; Linciano, P.; Puja, G.; Tait, A.; Borsari, C.; Denora, N.; Iacobazzi, R.M.; Brasili, L.; Sorbi, C. Novel Dithiolane-Based Ligands Combining Sigma and NMDA Receptor Interactions as Potential Neuroprotective Agents. ACS Med Chem Lett 2020, 11(5), 1028-1034.

28. Zampieri, D.; Grazia Mamolo, M.; Laurini, E.; Zanette, C.; Florio, C.; Collina, S.; Rossi, D.; Azzolina, O.; Vio, L. Substituted benzo[d]oxazol-2(3H)-one derivatives with preference for the sigma1 binding site. Eur J Med Chem 2009, 44(1), 124-130.

29. Hayashi, T.; Su, T.P. Sigma-1 receptor chaperones at the ER-mitochondrion interface regulate $\mathrm{Ca}(2+)$ signaling and cell survival. Cell 2007, 131(3), 596-610.

30. Penke, B.; Fulop, L.; Szucs, M.; Frecska, E. The Role of Sigma-1 Receptor, an Intracellular Chaperone in Neurodegenerative Diseases. Curr Neuropharmacol 2018, 16(1), 97-116.

31. Linciano, P.; Rossino, G.; Listro, R.; Rossi, D.; Collina, S. Sigma-1 receptor antagonists: promising players in fighting neuropathic pain. Pharm Pat Anal 2020, 9(3), 77-85.

32. Collina, S.; Rui, M.; Stotani, S.; Bignardi, E.; Rossi, D.; Curti, D.; Giordanetto, F.; Malacrida, A.; Scuteri, A.; Cavaletti, G. Are sigma receptor modulators a weapon against multiple sclerosis disease? Future Med Chem 2017, 9(17), 2029-2051.

33. Pal, A.; Fontanilla, D.; Gopalakrishnan, A.; Chae, Y.K.; Markley, J.L.; Ruoho, A.E. The sigma-1 receptor protects against cellular oxidative stress and activates antioxidant response elements. Eur J Pharmacol 2012, 682(1-3), 12-20.

34. Wang, L.; Eldred, J.A.; Sidaway, P.; Sanderson, J.; Smith, A.J.; Bowater, R.P.; Reddan, J.R.; Wormstone, I.M. Sigma 1 receptor stimulation protects against oxidative damage through suppression of the ER stress responses in the human lens. Mech Ageing Dev 2012, 133(11-12), 665-674.

35. Goguadze, N.; Zhuravliova, E.; Morin, D.; Mikeladze, D.; Maurice, T. Sigma-1 Receptor Agonists Induce Oxidative Stress in Mitochondria and Enhance Complex I Activity in Physiological Condition but Protect Against Pathological Oxidative Stress. Neurotox Res 2019, 35(1), 1-18.

36. Tsai, S.Y.; Hayashi, T.; Mori, T.; Su, T.P. Sigma-1 receptor chaperones and diseases. Cent Nerv Syst Agents Med Chem 2009, 9(3), 184-189.

37. Maurice, T.; Su, T.P. The pharmacology of sigma-1 receptors. Pharmacol Ther 2009, 124(2), 195-206.

38. Villard, V.; Espallergues, J.; Keller, E.; Alkam, T.; Nitta, A.; Yamada, K.; Nabeshima, T.; Vamvakides, A.; Maurice, T. Antiamnesic and neuroprotective effects of the aminotetrahydrofuran derivative ANAVEX141 against amyloid beta(25-35)-induced toxicity in mice. Neuropsychopharmacology 2009, 34(6), 1552-1566.

39. Villard, V.; Espallergues, J.; Keller, E.; Vamvakides, A.; Maurice, T. Anti-amnesic and neuroprotective potentials of the mixed muscarinic receptor/sigma $1(\sigma 1)$ ligand ANAVEX2-73, a novel aminotetrahydrofuran derivative. J Psychopharmacol 2011, 25(8), 1101-1117.

40. Su, T.P.; Hayashi, T.; Maurice, T.; Buch, S.; Ruoho, A.E. The sigma-1 receptor chaperone as an interorganelle signaling modulator. Trends Pharmacol Sci 2010, 31(12), 557-566.

41. Yao, H.; Yang, Y.; Kim, K.J.; Bethel-Brown, C.; Gong, N.; Funa, K.; Gendelman, H.E.; Su, T.P.; Wang, J.Q.; Buch, S. Molecular mechanisms involving sigma receptor-mediated induction of MCP-1: implication for increased monocyte transmigration. Blood 2010, 115(23), 4951-4962.

42. Calamita, G.; Ferri, D.; Gena, P.; Liquori, G.E.; Cavalier, A.; Thomas, D.; Svelto, M. The inner mitochondrial membrane has aquaporin-8 water channels and is highly permeable to water. J Biol Chem 2005, 280(17), 17149-17153.

43. Danielli, M.; Marrone, J.; Capiglioni, A.M.; Marinelli, R.A. Data of $\mathrm{H}_{2} \mathrm{O}_{2}$ release from AQP8-knockdown rat hepatocyte mitochondria. Data Brief 2019, 23, 103722.

44. Rossi, D.; Pedrali, A.; Marra, A.; Pignataro, L.; Schepmann, D.; Wünsch, B.; Ye, L.; Leuner, K.; Peviani, M.; Curti, D.; Azzolina, O.; Collina, S. Studies on the enantiomers of RC-33 as neuroprotective agents: isolation, configurational assignment, and preliminary biological profile. Chirality 2013, 25(11), 814-822.

45. Martinotti, S.; Pellavio, G.; Laforenza, U.; Ranzato, E. Propolis Induces AQP3 Expression: A Possible Way of Action in Wound Healing. Molecules 2019, 24(8), 1544. 
46. Yeung, Y.G.; Stanley, E.R. A solution for stripping antibodies from polyvinylidene fluoride immunoblots for multiple reprobing. Anal Biochem 2009, 389(1), 89-91.

47. Bradford, M. A rapid and sensitive method for the quantitation of microgram quantities of protein utilizing the principle of protein-dye binding. Anal Biochem 1976, 72, 248-254.

48. Rossi, D.; Pedrali, A.; Gaggeri, R.; Marra, A.; Pignataro, L.; Laurini, E.; Dal Col, V.; Fermeglia, M.; Pricl, S.; Schepmann, D.; Wünsch, B.; Peviani, M.; Curti, D.; Collina, S. Chemical, pharmacological, and in vitro metabolic stability studies on enantiomerically pure RC-33 compounds: promising neuroprotective agents acting as $\sigma_{1}$ receptor agonists. ChemMedChem 2013, 8(9), 1514-1527.

49. Guitart, X.; Codony, X.; Monroy, X. Sigma receptors: biology and therapeutic potential. Psychopharmacology (Berl) 2004, 174(3), 301-319.

50. Bolshakova, A.V.; Kukanova, E.O.; Gainullina, A.N.; Zhemkov, V.A.; Korban, S.A.; Bezprozvanny, I.B. Sigma-1 Receptor as a Potential Pharmacological Target for the Treatment of Neuropathology. St Petersburg Polytech. Univ. J. Phys. Math. 2016, 2(1), 31-40.

51. Cataldo, I.; Maggio, A.; Gena, P.; de Bari, O.; Tamma, G.; Portincasa, P.; Calamita, G. Modulation of Aquaporins by dietary patterns and plant bioactive compounds. Curr Med Chem 2019, 26(19), 3457-3470.

52. Calamita, G.; Perret, J.; Delporte, C. Aquaglyceroporins: Drug Targets for Metabolic Diseases? Front Physiol 2018, 9, 851.

53. Portincasa, P.; Calamita, G. Phytocompounds modulating Aquaporins: Clinical benefits are anticipated. Food Chem 2019, 274, 642-650.

54. Tesse, A.; Grossini, E.; Tamma, G.; Brenner, C.; Portincasa, P.; Marinelli, R.A.; Calamita, G. Aquaporins as Targets of Dietary Bioactive Phytocompounds. Front Mol Biosci 2018, 5, 30.

55. Sonntag, Y.; Gena, P.; Maggio, A.; Singh, T.; Artner, I.; Oklinski, M.K.; Johanson, U.; Kjellbom, P.; Nieland, J.D.; Nielsen, S.; Calamita, G.; Rützler, M. Identification and characterization of potent and selective aquaporin-3 and aquaporin-7 inhibitors. J Biol Chem 2019, 294(18), 7377-7387. 